\title{
. \\ ACID-RAIN INDUCED CHANGES IN STREAMWATER QUALITY DURING STORMS ON CATOCTIN MOUNTAIN, MARYLAND
}

Catoctin Mountain receives some of the most acidic (lowest pH) rain in the United States. In 1990, the U.S. Geological Survey (USGS), in cooperation with the Maryland Department of the Environment (MDE) and the Maryland Department of Natural Resources (DNR), began a study of the effects of acid rain on the quality of streamwater on the part of Catoctin Mountain within Cunningham Falls State Park, Maryland (fig. 1). Samples of precipitation collected on the mountain by the USGS since 1982 have been analyzed for acidity and concentration of chemical constituents. During 1982-91, the volume-weighted average $\mathrm{pH}$ of precipitation was 4.2. (Volume weighting corrects for the effect of acids being washed out of the atmosphere at the beginning of rainfall). The $\mathrm{pH}$ value is measured on a logarithmic scale, which means that for each whole number change, the acidity changes by a factor of 10 . Thus rain with a $\mathrm{pH}$ of 4.2 is more than 10 times as acidic as uncontaminated rain, which has a $\mathrm{pH}$ of about 5.6. The acidity of rain during several rainstorms on Catoctin Mountain was more than 100 times more acidic than uncontaminated rain.

\section{EFFECTS OF ACID RAIN ON SURFACE-WATER QUALITY}

Acid rain can affect the quality of surface water in two ways--by chronic acidification or by episodic acidification. Chronic acidification of a body of water results from a continuous input of acid rain over a period of years. This continuous acidic input to the body of water slowly causes changes in the water chemistry. If the acidic input continues unabated, the body of water eventually will no longer be capable of neutralizing the acidity and the water becomes acidified. A quantitative measure of the ability of a body of water to neutralize acidity is the acid-neutralizing capacity (ANC). A high ANC means that the water is capable of neutralizing large amounts of acidity, whereas a low ANC means that the water has little capacity to neutralize acidity and may become acidified. One of the major factors that determines how quickly or slowly a body of water will acidify is the type of bedrock or sediment underlying the watershed. For

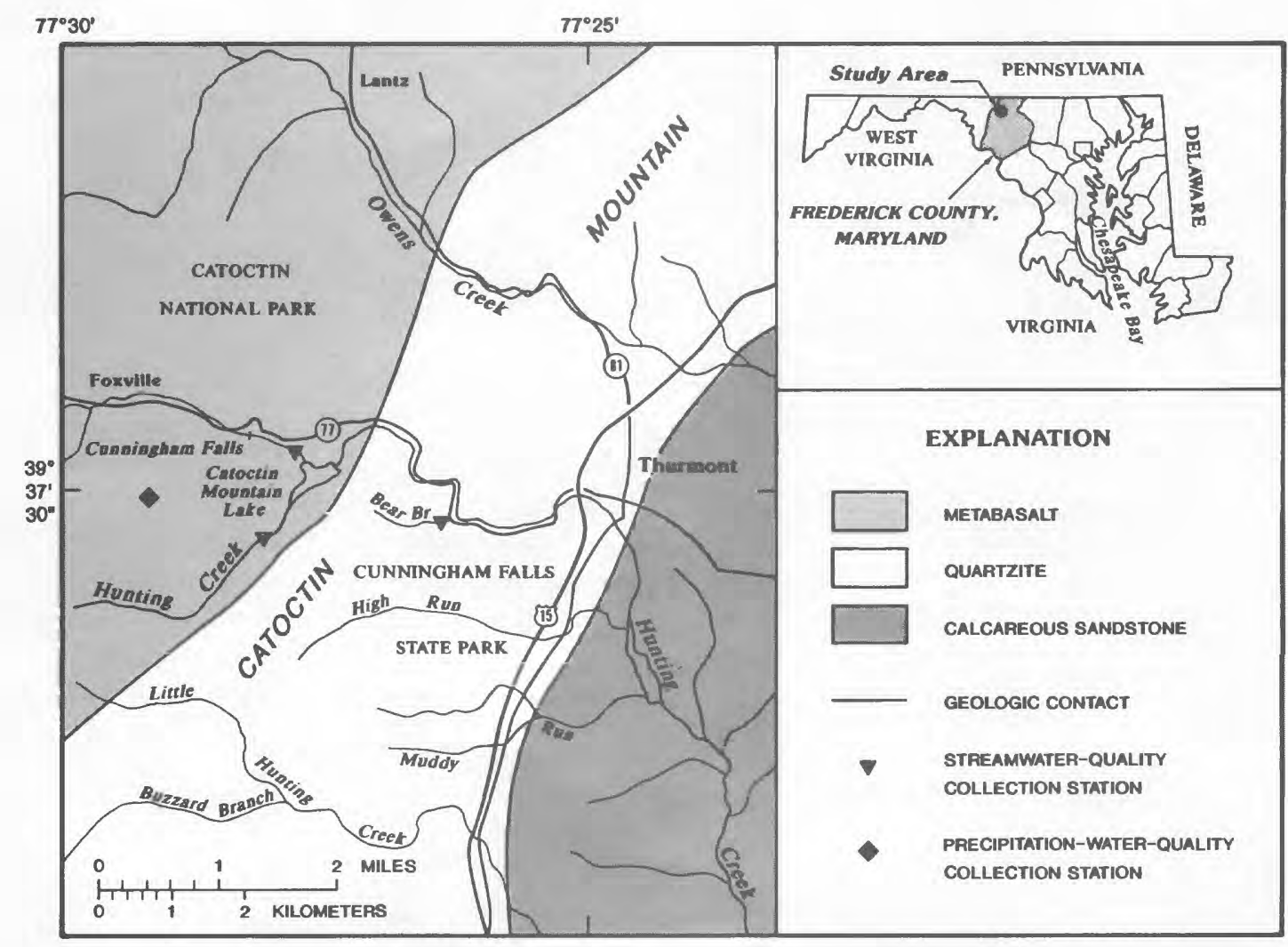

Figure 1. Location of the study area on Catoctin Mountain, Maryland, U.S. Geological Survey streamwater-and precipitation-water-quality collection stations, and generalized geology. 
example, water in a stream or lake that traverses or overlies limestone (composed of calcium carbonate) commonly has a high ANC and is said to be well buffered. In contrast, many lakes in the Adirondack Mountains of northern New York State are underlain by granite (composed of silicate minerals) and the water has a very low ANC; in fact, many lakes in the Adirondacks are acidified.

Episodic acidification of a stream or lake can happen over a relatively short time as a result of input from a single rainstorm or period of snowmelt. During a rainstorm, the acidic rain may be quickly routed by way of surface and shallow subsurface flow to the stream or lake, where the influx of acidic water causes the $\mathrm{pH}$ and ANC of the water to decrease. The decrease in $\mathrm{pH}$ and ANC can happen within minutes after the storm begins and the effect can last for hours or days. The amount of decrease in $\mathrm{pH}$ and ANC in a body
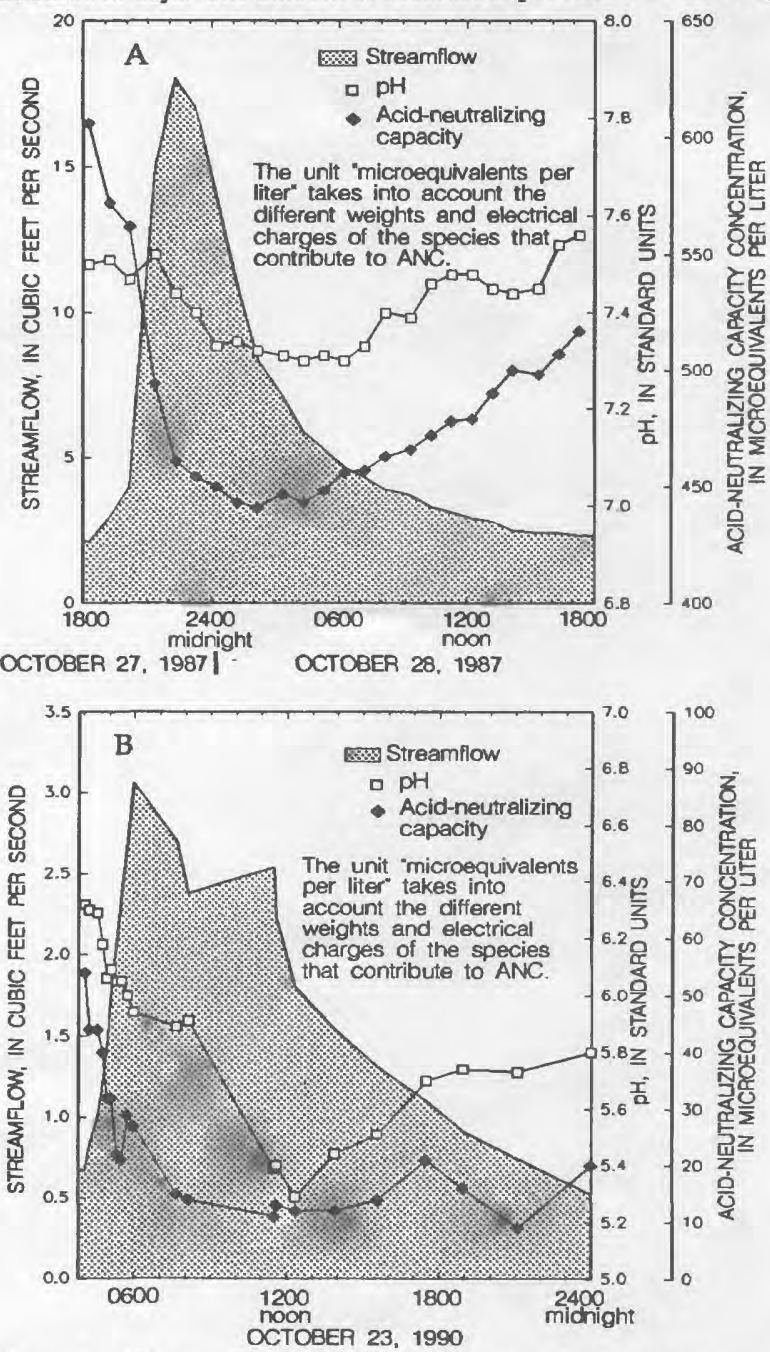

Figure 2.-- Effects of acid rain on water quality of two streams during rainstorms on Catoctin Mountain--(A)Wellbuffered watershed system, and (B) poorly buffered watershed system. (Note the differences in $\mathrm{pH}$ and ANC concentrations between the two watersheds.)

of water as a result of episodic acidification depends on many factors. The type of bedrock or sediment underlying the watershed affects the $\mathrm{pH}$ and $\mathrm{ANC}$ of the streamwater during non-stormflow conditions (base flow). A well-buffered watershed system (such as one underlain by limestone) will have a higher $\mathrm{pH}$ and $\mathrm{ANC}$ during base-flow conditions than a poorly buffered system (such as one underlain by granite). Even though the decrease in $\mathrm{pH}$ and ANC during a storm in a well-buffered watershed may be greater than in a poorly buffered watershed, the water quality generally does not deteriorate to a level harmful to aquatic organisms. In contrast, streams in poorly buffered watersheds can quickly lose all ANC, causing the stream to become acidified during storms. This sudden increase in acidity can cause aquatic organisms to suffer "acid shock." During rainstorms, a wellbuffered watershed with long flow routes may be able to neutralize most of the incoming acidity before it reaches the stream, and thus the stream will not experience a large amount of episodic acidification. A poorly buffered watershed with short flow routes will allow large amounts of acidic water to quickly reach the stream, thus causing a large amount of episodic acidification. In contrast to the preceding two examples, a watershed that is chronically acidified will be little affected by episodic acidification because the streamwater already has virtually no $\mathrm{ANC}$ and has the same $\mathrm{pH}$ as the incoming rain. Other factors that can influence the severity of episodic acidification include: intensity and duration of the incoming rain, $\mathrm{pH}$ of the rain, season (summer growing season as opposed to winter dormant season), and the length of time since the preceding rainfall, which affects the moisture content of the watershed and the shallow subsurface routes for the acidic rain to reach the stream.

\section{EFFECTS OF ACID RAIN ON AQUATIC ORGANISMS}

Chronic and episodic acidification can have harmful effects on the quality of surface water and aquatic organisms, including fish. As chronic acidification progresses, the number of individual species of fish and the organisms in the food chain that supports them slowly decrease until only acid-tolerant species, or in severe cases, no species, remain. As a result of episodic acidification of a water body, an entire population of fish may be destroyed by a sudden and drastic increase in streamwater acidity. Episodic acidification can be particularly damaging during the spring when many fish spawn and other organisms reproduce. Fish larvae and young fry are especially sensitive to acid shock. Episodic acidification of tributaries to Chesapeake Bay may be one cause of the decline of anadromous fish, such as rockfish, blueback herring, and alewives, in the bay. In the spring, these anadromous fish migrate to freshwater to spawn, and the sensitive larvae can be killed by a sudden influx of acidic water to a tributary.

\section{EPISODIC ACIDIFICATION OF STREAMS ON CATOCTIN MOUNTAIN}

Episodic acidification of streams on Catoctin Mountain has been documented by the USGS, in cooperation with MDE and DNR. Water quality of streams flowing on two types of Catoctin Mountain bedrock has been monitored: streams on metabasalt are well-buffered, and streams on quartzite are poorly buffered (fig. 1). During rainstorms, the $\mathrm{pH}$ and $\mathrm{ANC}$ of streamwater flowing on both types of bedrock declined (fig. 2). The changes were greater in the wellbuffered streams, but even under optimum conditions for episodic acidification, these streams did not lose all $\mathrm{ANC}$, and $\mathrm{pH}$ values remained in an acceptable range for survival of aquatic organisms. In contrast, the poorly buffered streams frequently lost most or all ANC during storms, and $\mathrm{pH}$ values declined to levels harmful to aquatic organisms. For these reasons, streams in well-buffered systems receiving acid rain usually support a healthy and diverse community of aquatic organisms, whereas nearby streams in poorly buffered systems exhibit an acid-tolerant aquatic community or may lack aquatic organisms.

For further information on these and related studies, contact:

District Chief, Water Resources Division

U.S. Geological Survey

208 Carroll Building

8600 LaSalle Road

Towson, Maryland 21286

K.C. Rice and O.P. Bricker

Open-File Report 92-649

November 1992 